\title{
The importance of fostering workplace wellness in pediatric radiology
}

\author{
Rama S. Ayyala ${ }^{1}$ (D) \\ Received: 14 October 2019 / Revised: 14 October 2019 / Accepted: 4 November 2019 /Published online: 6 March 2020 \\ (C) Springer-Verlag GmbH Germany, part of Springer Nature 2019
}

Pediatric radiology is an incredibly rewarding and fulfilling subspecialty. A common attribute shared by many pediatric radiologists is a strong sense of collegiality and camaraderie in the workplace. Traditionally pediatric radiologists have enjoyed a pleasant work environment with positive relationships among colleagues who share similar ideals. Unfortunately, this simple concept has become complicated in recent years. Studies have documented a high prevalence of burnout among pediatric radiology attending physicians [1] and have detailed contributing stressors [2]. Addressing the issue of burnout in pediatric radiology is not a simple process. It requires the efforts of individuals at many levels.

Hailu et al. [3] have taken on the important task of addressing the topic of physician wellness in a manuscript titled, "Walk in My Shoes: Interdepartmental Role Shadowing to Increase Workplace Wellness at a Large Pediatric Radiology Department." The program implemented by this group entailed having members of a pediatric radiology department shadow one another, allowing both clinical and non-clinical staff to become familiar with various roles in the department and allowing interactions among members who would not regularly have such an opportunity. The authors highlighted how this program instills the importance of building positive relationships, not just among physicians but among all members of a pediatric radiology department, which can help ultimately contribute to workplace wellness.

Regardless of the size of a pediatric radiology department, it can be difficult to regularly recognize individuals, especially with the increasing demands and complexity of tasks in

Rama S. Ayyala

rayyala@gmail.com

1 Department of Diagnostic Imaging,

Rhode Island Hospital-Hasbro Children's Hospital,

Warren Alpert Medical School of Brown University,

593 Eddy St, Providence, RI 02903, USA medicine. Creating programs similar to that described by Hailu et al. [3] can be helpful in bridging gaps between clinical and non-clinical staff in a pediatric radiology department, which might ultimately help improve departmental functionality. This method also allows individuals to be recognized for departmental contributions that might otherwise go unnoticed.

Workplace wellness is a broad term with a variety of definitions. However, one universal factor is a sense of collegiality and being a part of a team. Isolation has been identified as a potential risk factor for burnout in radiology [4]. This has been exacerbated by the technological advances in radiology picture archiving communication systems (PACS) and easy access to the electronic medical record (EMR) have decreased the need for face-to-face communication with others, both within radiology and with other clinical colleagues. Isolation can exacerbate stressful situations, whether these involve work-related stresses or personal issues, because of the feeling of lack of support and inability to lean on others. Programs such as Hailu et al.'s [3] can improve communication among colleagues, ultimately fostering a global feeling of respect and collegiality within a department. These programs need to be further developed and explored to help build stronger teams, ultimately facilitating workplace wellness and alleviating some of the triggers of physician burnout.

Pediatric radiology is an incredibly satisfying career. Unfortunately, over the last few years our subspecialty has sustained a decline in interest, with increased difficulty attracting trainees to pursue a career in pediatric radiology $[5,6]$. If we continue to foster the efforts championed by Hailu et al. [3], we might ultimately develop better work environments for trainees to experience the joy of what our subspecialty can offer, as well as to remind pediatric radiologists why we chose this fulfilling career path.

\section{Compliance with ethical standards}

Conflicts of interest None 


\section{References}

1. Ayyala RS, Ahmed FS, Ruzal-Shapiro C, Taylor GA (2018) Prevalence of burnout among pediatric radiologists. J Am Coll Radiol 16:518-522

2. Ayyala RS, Ahmed F, Ruzal-Shapiro CB, Taylor G (2019) Stressors contributing to burnout amongst pediatric radiologists: results from a survey of the Society for Pediatric Radiology. Pediatr Radiol 49:714 722

3. Hailu T, Ginader A, Nigro A et al (2019) Walk in my shoes: interdepartmental role shadowing to increase workplace wellness at a large pediatric radiology department. Pediatr Radiol
4. Harolds JA, Parikh JR, Bluth EI et al (2016) Burnout of radiologists: frequency, risk factors, and remedies: a report of the ACR Commission on Human Resources. J Am Coll Radiol 13:411-416

5. Pfeifer CM (2018) Declining interest in pediatric radiology prompts a call to action. J Am Coll Radiol 15:490-492

6. Pfeifer CM (2019) The impact of decreased interest in pediatric radiology. J Am Coll Radiol. https://doi.org/10.1016/j.jacr.2019.07. 029

Publisher's note Springer Nature remains neutral with regard to jurisdictional claims in published maps and institutional affiliations. 